\title{
Active Teaching of Primary School Pupils (I-III Grades) Using Mathematical Problems With the Content of Developmental and Interdisciplinary Skills ${ }^{1}$
}

\author{
Tamar Dograshvili \\ Akaki Tsereteli State University \\ Department of Pedagogy, Georgia, Kutaisi \\ Tamar The Queen N59, Postal address - 4600
}

\begin{abstract}
Building the educational process in primary school on an active teaching, which is implemented by including mathematical problems with the content of developmental and interdisciplinary links in math classes makes the learning process intresteing and attractive and increases pupils' interest. The paper dwells on the methodology for working out the systems of mathematical problems with the content of developmental and interdisciplinary links, which is based on the original scheme that we developed. There has been developed the methodology for teaching how to solve mathematical problems with the content of developmental and interdisciplinary links in primary school, psychological and pedagogical patterns of realizing these problems, indicators of including them in the teaching process and the results of the educational experiment, confirming that the the original approaches realized in this work ensure higher quality of mathematics education of primary school pupils and their inclusion in an active teaching using the systems of specially selectedproblems.
\end{abstract}

Key words: developmental mathematical problems; research skills; interdisciplinary links; active teaching

\section{Introduction}

\subsection{The essence of research}

In the first grade, pupils are involved in the process of active teaching(Stella V, 2001) and it is therefore important that teaching process is iteresting for pupils, has developmental function, forms and develops logical thinking(Batchelor S, Torbeyns J, Verschaffel L, 2019) does not limit pupils' freedom, makes learning as enjoyable for them as playing( Godfrey J, Stone J, 2013)and ensures that pupils have school readiness. At the same time, however, it'sthe question on how to achieve all this? How to make math classinteresting and attractive for pupils?(Ginsburg H, Lee S, Boyd S, 2008)in the lower grades, mathematics is associated with solving problems, that is, we should look for the key in the problems. What is our situation today?(Elmore R, Peterson P, McCarthy J, 1996)It may be said without exaggeration that situation is bad, even regrettable. School mathematics textbooks cannot ensure pupils' interest because of likeness of problems and ways to solve them, which makes the teaching process in the lower grades boring and annoying.

\subsection{Problem description}

The inclusion of mathematical problems with the content ofdevelopmental andinterdisciplinary links in teaching practice of primary school pupilsis one of the crucialissues of didactics, which is a combined approach to teaching. Each component of such teaching-separately the problems and problems containing the developmental and interdisciplinary links - is increasingly relevant, and each component of teaching is the subject of a special study.

One promising way of improving teaching subjects is based on active teaching (Andres H,2019)which can be achieved both by including the separate developmental mathematical problems in the process of teaching and by implementingthe interdisciplinary links in this process. Each component significantly raises the level of knowledge of primary school pupils and provides them with a broad general education. Higher and public schools do not classify the systems of problems required for combined teaching, and methodological specifics of solving such problems are not elaborated.

${ }^{1}$ Research was conducted under financial support from ShotaRustaveli National Science Foundation (SRNSF), Grant (№ YS 17_80) „Active training of primary school pupils (I-III grades) by using mathematical problems with developmental and inter subject communications content" 
In order to solve this problem, we felt it necessary to:

- To study and identify the essence, specifics, purpose and function of the systems of mathematical problems with the content of developmental and interdisciplinary links for primary school pupils;

- To determine the classification criteria for these systems;

- To work out the systems of mathematical problems with the content of developmental and interdisciplinary links for primary school pupils;

- To develop methodology for working out the systems of mathematical problems with the content of developmental and interdisciplinary links for primary school pupils, as well as methodology for teaching how to solve them.

Scientific value of this work is the development of psychological-pedagogical and methodological frameworks for working out the systems of mathematical problems with the content of developmental and interdisciplinary links, working out the systems of such problems and including them in the process of teaching primary school pupils, and the practical value (Ginsburg H, Klein A, \& Starkey P, 1998) is improving the quality of mathematics education of primary school pupils (I-III grades), and including them in the process of active teaching as the" Learning requires the active, constructive involvement of the learner" (Stella V, 2001)by means of the systems of specially selected problems.

\subsection{Goal of research:}

- To develop theoretical foundations, methodological approaches and criteria for teaching to solve the systems of mathematical problems with the content of developmental and interdisciplinary links for primary school pupils (I-III grades).

- To develop solving techniques and teaching methodology of the systems of mathematical problems with the content of developmental and interdisciplinary links for primary school pupils (I-III grades).

- To work out the systems of mathematical problems with the content of developmental(Wickstrom H, Pyle A, DeLuca C, 2019) and interdisciplinary links for primary school pupils (I-III grades).

- To develop the methodological approaches, which will help primary school pupils (I-III grades)in developing their practical skills and active learning by solving the systems of mathematical problems with the content of developmental and interdisciplinary links.

- To incorporate the process of teaching into a single system by using the systems of mathematical problems with the content of developmental and interdisciplinary links for primary school pupils (I-III grades).

- To raise general level of education.

- To improve the quality of mathematics education of primary school pupils; (Frye D, Baroody A, Burchinal M, Carver M, Jordan C, McDowell J, 2013).

- To encourage readiness of primary school pupils for active learning(Elbahri M, SolimanA, Yliniemi K,Abdelaziz R,Homaeigohar S,Zarie E, 2018) through mathematical problems with the content of developmental and interdisciplinary links.

- To work out the new methodological approaches and recommendations through the implementation of mathematical problems with the content of developmental and interdisciplinary links for primary school pupils.

\subsection{Sub-goal of research}

- To implement the teaching process for primary school pupils by including mathematical problems with the content of developmental of interdisciplinary links.

- To scientifically determine the advantageof the inclusion of mathematical problems with the content of developmental and interdisciplinary links in the process of teaching for primary school pupils, as compared to traditional teaching.

\subsection{Objective of research:}

- To justify the need for the inclusion of mathematical problems with the content of developmental and interdisciplinary linkstheteaching process for primary school pupils.

- To develop a methodology for working out the systems of mathematical problems with the content of developmental and interdisciplinary links and special techniques for solving them in the process of teaching for primary school pupils.

- To create a single system of teaching through the implementation of the systems of mathematical problems with the content of developmental and interdisciplinary links and work out the relevant methodological recommendations in the process of teaching for primary school pupils.

- To introduce the research findings in teaching practice for primary school pupils. 


\subsection{Novelty of research}

- We have studied psychological, pedagogical and methodological patterns of implementation of the systems of mathematical problems with the content of developmental and interdisciplinary links for I-III grades, indicators of the inclusion of the systems of these problems, and expected educational outcomes.

- We have studied a methodology for working out the systems of mathematical problems with the content of developmental and interdisciplinary links for I-III grades and have developed specific methodology to solve them that provides the basis for providing teachers, pupils, experts, and education stakeholders with new methodological recommendations.

\subsection{Target of research}

- Mathematical problems considered in the process of teaching for primary school pupils (I-III grades).

- The process of teaching the systems of mathematical problems with the content of developmental and interdisciplinary links intended for active teaching in I-III grades.

\subsection{Research strategy}

The study included the qualitative and quantitative components, and was carried out in four phases:

\section{Qualitative component}

The quantitative component was preceded by the qualitative study aimed to identify indicators for assessing the quality of teachingprimary school pupils for aquantitative component. Within the qualitative component, the focus groups(respondents) were questioned, including education experts, school principals, resource centers, parents and teachers. The qualitative component was implemented within the first six months from the beginning of the study.

\section{Quantitative component}

The purpose of a quantitative component is to collect information from the target groups - teachers, school principals, education experts, resource centers, and parents of pupils, according to indicators identified within the qualitative component.

We deemed it optimal to use a random walk method.

\subsection{Selection method}

We used the stratified random selection to select schools, for which we used a geographic region and type of settlement as stratification variables:

1.Schools in the mountainous regions

2.Village schools

3.Urban schools

Respondents in each region/settlement were selected using the random walk principle.

\subsection{Research findings}

- Psychological-pedagogical and methodological bases of mathematical problems with the content of developmental and interdisciplinary links for primary school pupils were developed and scientific and methodological analysis of school math textbooks for 1-II grades was conducted.

- The major disadvantage of traditional teaching stems from the lack of methods and techniques for solving mathematical problems, which makes monotonous problems and exercises boring. Through the psychological and pedagogical approaches, the need has been justified for the inclusion of special techniques of solving mathematical problems with the content of developmental and interdisciplinary linksin I-III grades, which is the way for active teaching of primary school pupils.

- We developed a methodology for teaching how to solve and compose problems in conjunction, which allows teacher for composing mathematical problems from the the pupils' field of interest that will have the statement with the thematic content attractive to them.

- Methods for solving specially selected mathematical problems and a special methodology for their teaching in the lower grades were developed. In particular: exercises with the content of interdisciplinary links of mathematics and nature study andmethodology for teaching how to solve them. The emphasis is placed on the modern methodological approaches to solving.

- The systems of mathematical problems with the content of developmental andinterdisciplinary links for primary school pupils were selected separately for I, II and III grades. We composed 400 problems for each grade with answers and guidelines. 
- We worked out methodological guidelines for math teachers.

\section{II- Methodology}

We used various research methodologies, in particular historical, comparative, descriptive, evaluationresearch and so on.

We used historical research when it was necessary to establish the effectiveness of teaching the issues discussed in the past and to draw conclusions. For example, when studying the psychological and pedagogical bases of mathematical problems with the content of developmental and interdisciplinary links for primary school pupils, we consideredthe approaches implemented in the past, as well as when analyzing the school mathematics textbooks for 1-III grades and so on.

We also used comparative research when using historical research to compare different research materials and to identify the benefits of the implemented method of research. In some cases, we needed to observe directly observant the process of teaching to generate the required information needed, in order to inspect the different situations and special cases. In this case, we used descriptive research. The evaluation research was used mainly when we conducted statistical analysis of studies performed as a result of traditional teaching outcomes and approaches that we developed.

We assessed the result of the evaluation researchusing statistical criterion $\chi^{2}$ that confirmed the advantage of the methodological approach used. Studies carried out using statistical methods have proven a progress in the educational performance of pupils, a shift to active teaching and improvement of the quality of general education through the use of the systems of mathematical problems with the content of developmental and interdisciplinary links.

We appliedresearch with system analysis, which we performed in phases:

- The material reviewed was broken down into several parts;

- We assessed each part;

- We received the final result.

The presented methodology provides high scientific quality of research, as well as the reliability and validity of the results obtained.

\subsection{Stages of research}

\section{Research was carried out in four stages:}

I-stage- A survey of the existing math teaching-learning situation in I-III grades of public and private schools. Identification of capacity constraints and strengths. Assessments, establishing anaction plan. In parallel, we started to composemathematical problems with the content of developmental and interdisciplinary links.

II-stage- Implementation of the action plan, development of theoretical and practical issues required for active teaching. Holding the trainings for insight intothe materials developed, for I-III grade teachers and specialists.Composingmathematical problems with the content of developmental and interdisciplinary links.

III-stage- Including the developed materials in the process of teaching. Methodological supervision and control over the teaching process. Adjustmentsto the plan, where necessary; developingthe corrected issues. Holding trainings on the materials developed.Composingmathematical problems with the content of developmental and interdisciplinary links.

IV stage - Assessing the results obtained using statistical criteria. Drawing conclusions.

Based on our research, we have established that majority of primary school pupils do not like to solve mathematical problems, because they are bored to solve typical problems(Beilock S,Maloney E, 2015). And we can say that by solving such problems, it is impossible to achieve high levels of logical thinking among pupils, and they cannot raise pupils' intelligence. Therefore, we started to think about developing different approaches for primary school pupils to mathematical problems that would make the learning process fun and give it a developmental function as well(MarottaM, Hargis J, 2011). To find out the thing the primary school pupils love and interested most, we conducted a survey. More than 900 pupils were involved in this survey. The results of a survey showed that most of all, pupil love watching cartoons and their characters (34\%), fairy tales and their characters (23\%), children's computer games (21\%), works of fiction and movies about the pirates, deserted islands, and treasure hunters (16\%), and other children's games $(6 \%)$.

After analyzing these data, we decided to compose mathematical problems for primary school pupils based on the following principle:to compose the problem statement so that we introduce in it their favorite favorite fairy tale and cartoon characters, pirates, treasure hunters, and so on, in accordance with age development of pupils, while in terms of the content, the problems have a developmental content that is, to compose such problems, whose solution requires searching, or in other words, the non-standard mathmeticallympiad problem. The practice shows that pupilslike to take 
part in the process of solving such problems (the statistical evaluation of the educational experiment is shown below), while also showing the low interest in solving problems from typical school textbooks. Why dopupilshave particularly positive attitude towards such problems? What is the main reason for this? The answer to this question is simple. The problem statementis attractivefor pupils and they enjoy reading it without coercion. After reading the problem statement, the teacher, by putting the questions within one-to-two minutes,revivesthe pupils' favorite magic world and characters that inspires pupils' readiness to solve the problem. And the problem, with its structure, has the developmental content, its solution requires searching, intellectual discipline, which develops logical skills in pupils and creates a prerequisitefor solving problems with the same content in the future as well, that is, the scheme that we developed helps primary school pupils to solve developmental problems without coercion, which develops their logical thinking and promotes in-depth and profound learning of mathematics, raising their intelligence. We have considered such developmental problems that are solved by applying the Dirichlet principle, analogy, generalization, invariants and semi-invariants, the use of incomplete and complete inductions, analytical and synthetic methods, deduction, the use of generalization techniques, graphs, ordered couples, analogy, test and sampling method, combinatorial and probabilistic problems containing the elements of the theory of sets and so on. Of particular interest to primary school pupilswerelogical problems and fluid transfer problems. To question - in what grade should we start solving developmental mathematical problems, I answer that the inclusion of developmental mathematical problemsin the teaching process in math class, should be started from first grade and continued then in all grades. During one lesson, we have to solve one or two problemsof suchcontent and no more than one problem should be given to pupils as homework, which is similar to problem that was considered during school classes, nut its complexity is relatively lower. I would also like to note that only the teacher decides on the topic, the extent, content and complexity of problem to be included in the process of teaching, since it depends on the psycho-physiological abilities of pupils(Berk E \&Winsler A, 1995), the level of their mathematical knowledge, their age development and so on.

- We worked out the system of mathematical problems with the content of developmental and interdisciplinary links for primary school pupils according to the scheme that we developed:

„Transfer of knowldee from discipline A of primary classes (not from mathematics) $\rightarrow$ mathematical problem with the content of discipline A, the statement of which is associated with knowedge transferred to pupil $\rightarrow$ solving the mathematical problem set $\rightarrow$ after writing down the answer to the solved problem, pupils are given questions, which strengthen their knowledge in discipline A“.

- For primary school pupils, we developed the forward and backward interdisciplinary limkages between mathematics and nature study, mathematics and fine and applied arts. The forward interdisciplinary linkage implies explaining any particular event or fact in other discipline using mathematical methods. The backward linkage implies proving particular mathematical provision, or solving mathematical problem using methods and approaches from other discipline. To compose mathematical problems with the backward interdisciplinary linkages for primary grades, we used the scheme that we developed:

„Mathematical problem with the content of discipline A (not mathematics) for primary grades $\rightarrow$ solving the mathematica problem $\rightarrow$ a numerical value of answer to solved problem enhances or/and strengthens the knowledge acquired by pupil in discipline A“.

- Based on this and the questionnaire surveys of teachers, we identified the key topics, during examination of which, the inclusion of the systems of problems containing interdisciplinary links would be most effective. These topics are: the systems of mathematical problems ofenvironmental content with interdisciplinary links, the systems of mathematical problems with the content of ethnographic tour with interdisciplinary links, the systems of the astronomy and space-related mathematical problems with interdisciplinary links, the systems of the economics and finance-related mathematical problems, the systems of mathematical problems related to healthy life-style with the content of interdisciplinary links and so on. Given the psycho-physiological state of primary school pupils, we decided that when implementing interdisciplinarylinks establishedaround any topic, it is necessary to follow the scientific principle, which implies that the theoretical knowledge transferred to pupils or any particular data contained in mathematical problem mustreflect factual and scientifically justified information, since pupils easily memorize numerical values, and if later the information that they obtained from other sources does not match the data already known to them, this may disappoint them.

To that end, we deem it necessary that the teacher, who decided to include the systems of mathematical problems with the content of interdisciplinary links in the teaching processfor primary school pupils, has to create first the information base around the topic, which will reflect real numerical data, on the basis of which, the teacher will compose mathematical problem with interdisciplinary links. We'llconsider briefly how we worked out the systems of mathematical problems with interdisciplinary links around the above stated topics. 
- The process of teaching in primary school is active and effective when the teacher is able to involve all pupils in the the process. When is this achieved? While the topic of the lesson is interesting to pupils in terms of content, when they already have some knowledge about the topic of the lesson that they are trying to demonstrate in front of the class"Classroom innovation can involve finding unique ways to present material to students. Engaging students with the material will support their understanding of the broader implications of what they learn and how it relates to their lives" (Ronald Morris, 2018). Such topics may vary in the senior classes, while in primary school the teacher has nomuch choice, since range of knowledge of primary school pupils is not wide and deep. The issues that teacher can include in the process of teaching in primary school are the environmental education issues, which are of high relevance by nature and can be used thematically to establish interdisciplinary links. We believe that more attention needs to be paid to the nature and environmental education of pupilsat school from the very beginning of their education, since environmental issues area global problem and all humanity is involved in solving them. From a scientific perspective, the goal environmental education is achieved when the following objectives are solved on the whole:

- Awareness-raising - that is, acquiring knowledge of environmental issues and ways toaddress them.

- Educational -promoting a healthy lifestyle among pupils and motivating them towards environmentally targeted actions and behavior.

- Developmental -extending the pupils' intellectual and practical knowledge, wildlife studies, its critical evaluation, design and implementation, with teacher, of environmental measures.

Explanation and study of teaching materials with an environmental content takes place mainly during classes of nature study, fine and applied arts, mathematics and native language,where, in a form accessible for pupils, there were considered the links between animate and animate nature, as well as between various components of animate nature (plants, animals, etc.)andnature and human beings. In the later period, pupils get acquainted with the world around and establish the environmental links there that help them in establishing the logical links.

In teaching practice in primary school, it is reasonable to use in the environmental education field trips, whose purpose and function is practical implementation of environmental issues with the content of courses ofnature study and other disciplinesand their examination, which is reflected in the observation of plants and animals, as well as some production processes described in the teaching materials, visiting historical sites discussed in classroom materials, verification of data given ina statement of mathematical problem of an environmental content, which referred to the height and age of trees and plants, and so on.These environmental education field trips arouse pupils' interest, pupils go outdoors, to the enterprise or factory, get acquainted with some of the manufacturing processes, make measurements, weighing that help them to develop practical skills. Sometimes, especially in the lower grades, it is also reasonable to organize the simulated education field trips. During the environmental education field trips, pupils have the opportunity to measure and verify their own some data that they will use later in solving mathematical problems of an environmental content.

It is methodically justified for primary school math classes to include mathematical problems of an environmental content with developmental and interdisciplinary links, in particular, when examining mathematical problems of relevant content. The process of teaching implemented in this way does not need to provide greater time for teaching, but it has a high developmental effect of pupils, because by incorporating problems with such content, the process of teaching is incorporated ita single system, which promotes active teaching of pupils, the creation of a new knowledge and modern teaching methodology, on the basis of relevant recommendations are working out. It is also reasonable to examine mathematical problems of an environmental content with developmental and interdisciplinary links during extracurricular, facultative and math circles activities. Mathematical problems of an environmental content with developmental and interdisciplinary links are virtually absent from the primaryschool mathematics textbooks, and therefore the teachers have to compose them, for which, as we said above, the teachers first need to develop a database containing the available information on environmental issues related to the flora, fauna and so on. For example, data related to tree species life, tree height, environmental significance of forest, the environmental role of birds and insects in nature, the length of rivers, the spaces between different human settlements, the distance from Earth to moon, from Earth to the sun, country's national parks, nature reserves, etc. It is advisable to write down the collected data in a table format, which will then help pupils to compose differentmathematical problems of an environmental content.

- Practice shows that innovative approaches in primary school are based on the interdisciplinary links, which can be even more effective if we use a new form of interdisciplinary linksin primary school, such as ethnographic tour. When conducting an ethnographic tour, pupils and teachers have the opportunity to independently collect data that they will use as a database and, based on them, the teacher composes mathematical problems with interdisciplinary linksrelevant to the topicof ethnographic tour and includes them in theteaching practice inprimary school. 
The situations described in such mathematical problem are known to pupils, they have already seen and experienced them, which makes it easier for pupils to perceive the problem situation, to understand its content, which arouses their natural interest in solving this problem. After the completion of ethnographic tour, pupil should be able to develop the right attitude towards the selected ethnographic issue, ensure its observation and gather the necessary material surrounding the ethnographic issue, integrate the existing interdisciplinary knowledge and use in practice the acquired knowledge in separate disciplines.

- Before working out the systems of mathematical problems with interdisciplinary links related to astronomy and and space, we collected the required data on the Earth, a satellite of the Earth - the moon, and lunar phases, then we introduced pupils to information about the first living creatures sent into space, provided them with information about the first spacemen, the first women in space, the records set in space, artificial satellites, and much more. Based on this data, we then worked out the system of mathematical problems with the content of interdisciplinary links, developed exercises, requiring to fill in the gaps in the text, and then we launched a mathematical quiz on space exploration.

- We paid special attention to the promotion of a healthy lifestyle for improving the health of primary school pupils, becausemany primary school pupils are not well aware of the basic detailsof a healthy lifestyle. A healthy way of living is a prerequisite for human health, longevity, and discharging responsibilities fully. It contains numerous components. We separated the basic parts from them:

- Acquiring health skills, health skills development starting in early childhood;

- Ensuring the safety of the outside world, studying its impact on human health;

- Discarding unhealthy habits(tobacco, alcohol and drug consumption);

- Eating in moderation, according to individual and physiological characteristics. Awareness of the quality of used products;

- Movement -a physically active life, including special physical exercises in day mode, taking into account age and physiological characteristics;

- Hygiene - personal and social hygiene, knowledge of first aid basic skills;

- Toughening up.

We collected the required data on these basic parts and then worked out the system of mathematical problems with interdisciplinary links, and then we included them in the process of teaching. In particular, we worked out the systems of mathematical problems with interdisciplinary links relatedto the human/pupil's body and mathematics, healthy nutrition and mathematics, healthy lifestyle and mathematics, bad habits and mathematics. We specifically addressed the road traffic regulations and mathematics. I believe that primary school teachers must regularly remind pupils of the elementary rules of the road traffic, when to cross the street according to a walk sign, not to play and not to cross the car traffic way, the need for a specialseat for adolescents in a car, and so on.

- The socio-economic transformations taking place in the world brought about changes in the standard of living of people, which has puton the agenda the adaptation of individuals to the demands of the modern market economy. The solution of these challenges is closely linkedwithpupils'educational level in economics, which in my vision,must be one of the focus areas in all levels of education. It is methodically acceptable and appropriate that consideration of mathematical problems of an economic content should start in primary school, to which end, it is necessary to develop the methodological aspects of teaching mathematical problems of an economic content in in the early grades, which involves training of all pupils at elementary level in economics. When teaching mathematical problemsof an economic content,the teacher has a concrete task to transfer the transfer the basic economic knowledge to pupils, which may relate to individual economic behavior, family economy or industrial-economic processes, the forms of ownership, various types of work organization, the basics of social and economic security of young people and so on. It should be noted that the basic economic knowledge alone is not the basis for the formation of economic education of individual. The active position of each primary school pupil in the process of economic education allows for choosing the way ofpersonal development of all pupils, which defines the range of self-realizationof pupils, thus guaranteeing the acquisition of other economic knowledge and skills in a modern market economy. In the process of economic education of pupils, the economic knowledge is transformed into the findings that are realized in behaviors and manners, in which by their economic needs and personal interests are the driven force, which in turn depends on the economic culture of society.

Teaching economics to primary school pupils is a social mandate of society. Their economic education should be implemented indifferent directions as follows: Introduction to economic education of primary school pupils in the main disciplines; Integrated course for economic education of primary school pupils; The inclusion of a special economic education course in the teaching process of primary school pupils, etc. 
Unfortunately, in most primary schools, almost nothing is done in terms of economic education, and in schools where the economic issues are introduced to pupils only of the own volition of primary school teachers, this process goes disorderly and spontaneously. This is due to the lack of teaching methodological literature for primary school pupils related to teaching the economic issues. According to the interviewed teachers, experts and economists, the main reason for the low level of economic knowledge and economic education is non-systemic teaching. First of all, this is why the primary school teachers are not scientifically and methodologically in economics. The second reason is that teachers use traditional approaches, methods and techniques when teaching the economic issues that do not take into account the specifics and features of teaching the economic issues. The third reason is that there is existing acommon approved vision of what economic issues should be studied by primary school pupils. The fourth reason is that, despite the numerous scientific and methodological works in economics, the psycho-pedagogical foundations of the economic issues for primary school pupilsbased on their age and psycho-physiological capabilitieshave not yet been developed so far. To date, no coherent methodological system has been created that provides pupils withthe required material of economic nature, the teaching of which will be provided by a didactic movement from simple to the complex, and will be consistent with the pupil's age and psycho-physiological capabilities and responds to modern requirements of teaching economics. Our approach to teaching economics to primary school pupils is as follows:

- Since economics in primary is not taught as an independent discipline, the economic issues should be taught within the main teaching courses (math and native language) by including the economic issues - using the interdisciplinary links;

- The teaching process should be conducted without any coercion; the emphasis should be placedon teaching practical everyday matters, for which simple household economic problems should be used;

- Economic problems should be included in primary school math class, when the teacher explains, proves or repeats a particular arithmetic operation, or uses a particular approach, while the the problem of an economic content is solved using the same operation or a specific approach;

- Teaching the economic issues in this form in primary school requires neither adding the teaching discipline nor the additional teaching time;

- The implementation of interdisciplinary links in primary school pupils will contribute to the country'ssocial andeconomic development, while the issues of the formation of economic cultures of primary school pupils become part of a key strategic problem in the educational system.

I have developed methodological approaches to solving mathematical problems of an economic content that are compatible with the third grade mathematics course. During class, I offerpupils to transform mathematical problems into lessons in a way that expresses simple concepts of economics, the relationships and operations between the economic concepts.By solving such problems, pupils become familiar with the economic concepts, perform the particular operations and arithmetic calculations. By solving the economic problems, math class becomes more meaningful and diverse, and it activates and the students 'mental activities, enriches and extends thepupils' knowledge with mathematical and economic terms, facilitates the acquisition of basic knowledge of the economic issues and accustoms pupils to the rules applicable to the correct and economically beneficial behavior undermarket economy conditions, helps them in the analysis ofthe factual situations, to find independently the right solutions theoretically and practically implement them. Solving the problems of an economic content in primary school math class helps teachers to bridge the gap between the living needs and the pedagogical process.

- When working out the systems of problems with content of developmental and interdisciplinary links for primary school pupils, we used the following scheme:

„Problem $\rightarrow$ theory $\rightarrow$ problem“.

Through this approach, pupils are able to learn better problem solving, and they consider the theoretical and practical issues of the subject as an integral unit, which is important when studying the disciplines such as mathematics and nature study.

- When teaching solving and composing mathematical problems with content of developmental and interdisciplinary links for primary school pupils with reference to each other, we used the following schemes:

$$
\text { „Sameness } \rightarrow \text { equation“and,,Sameness } \rightarrow \text { equation } \rightarrow \text { problem“. }
$$

\section{III- Experimental validation of findings}

Solving these and similar problems in primary school serves to form pupils' positive attitude towards mathematics,as well as to increase the level of teaching, as evidenced by four pedagogical experiments that we conducted in schools during four semesters. The experiment involved 605 pupils from primary schools in different regions (high mountain, rural and urban regions). 
We divided the primary pupils involved in the experiment into two groups: in one group we grouped together pupils from schools, where the systems of mathematical problems containing developmental and interdisciplinary links are included in the teaching process, while in the second group, we grouped pupils from schools, where the teaching process does not include such systems of mathematical problems. The experimental study was conducted in two phases on three forms during four semesters. Prior to the pedagogical experiment, we analyzed written tests and independently performed papers, which would concern issues considered in the paper. During the preparatory experiment,we identified the topics, during examination of which, we deemed it possible to includein the teaching process the systems of mathematical problems containing developmental and interdisciplinary links, and we developed its teaching methodology, which subsequently, during practical work, underwent insignificant changes. The educational experiment demonstrated the effectiveness of the inclusion ofthe systems of mathematical problems containing developmental and interdisciplinary linksin the teaching process. The age of the participants in the experiment is 8-10 years. Of 605 pupils, 319 were girls and 286 were boys.I would like to note that based on the results, involvement of boys and girls in the experiment had no any significant differences, all the results of the experiment were fully consistent with the average results for both boys and girls, so no gender difference issuesdid not require consideration during the experiment(Vukovic R, Lesaux N, 2013).

The specific issues considered in our work are virtually absent from primary school textbooks for mathematics, and regarding those separate problems, that we may find in the textbooks are not in systemic form, it can be said that teachers fail to pay due attention to them. Therefore, our primary focus was on teaching to solve mathematical problems containing developmental and interdisciplinary links in primary school based the materials that we gathered. During the pedagogical experiment, we used math textbooks, problems taken from the supporting teaching materials, and problems that we specially composed.

The experimental study was conducted in two stages on three forms of teaching:

First stage- The preparatory experiment was conducted in classes, facultative and math circles activities, during which mathematical problems were considered, taken from school textbook and mathematical problems containing developmental and interdisciplinary links that we composed on the basis of data that we gathered.

Second stage - The educational experiment was conducted in classes, facultative and math circles activities.

The purpose of the preparatory experiment was to test the pupils' level of mathematical knowledge. We were particularly interested inpupils' skills of solving mathematical problems containing developmental and interdisciplinary links composed in accordance with the curriculum, which allowed us checking the degreewhich acquired knowledge wasrealized in practice-how did they usewhen solving these problems.

During the preparatory experiment, in math classes, facultative and math circles activities, we included in the teaching process the mathematical problems containing developmental and interdisciplinary links composed in accordance with the themes of primary school curriculum, which does not require the additional time for teaching.

Based on the results of the preparatory experiment, we can draw conclusions as follows: in order to identify the benefits of includingand targeted teaching the systems of mathematical problems with the content of developmental and interdisciplinary links in the teaching process in primary school, it was necessary to conduct the educational experiment, we analyzed the available modern methodological literature on interdisciplinary links of developmental and primary school mathematics, which we adapted to the topics of primary classes. We selectedthe methodological approaches that are acceptable to us and mathematical problems whose solution gives us a significant time effect anddevelopspupils' logical thinking. We set out a practical work plan. In addition, we selected and elaborated the issues, which would be necessary to elaborate a theoretical basis, which will ensure the methodically sound inclusion of mathematical problems with developmental and interdisciplinary links in primary school math classes. In other words, we have developed the theoretical foundations for including mathematical problems with developmental and interdisciplinary links in the teaching process in primary school. To this end:

- We determined the relationships between mathematical problems containing developmental and interdisciplinary links composed in accordance with the themes of primary school curriculum, and problems to be considered within a school course in mathematics;

- We developed the methodological underpinnings for including mathematical problems with developmental and interdisciplinary links in the teaching process;

- We identified the goals and objectives of including mathematical problems with developmental and interdisciplinary links in the teaching process; 
During the educational experiment, we used the databases that we collected, and on that basis we developed mathematical problems containing developmental and interdisciplinary links that we included in the teaching process. Some of them we discussed during classes, facultative and math circles activities, some of which we gave them for the independent work. The main goal of the educational was to confirm the effectiveness of the inclusion of mathematical problems with developmental and interdisciplinary links in the teaching process, and improving mathematics education through the inclusion of interdisciplinary and developmental problems in the teaching process. The educational experiment lasted for five semesters. We did our first checkup at the beginning of the experiment. During this checkup, pupils had to solve mathematical problems containing developmental and interdisciplinary links, pretty much of the same type as in the preparatory experiment. This task was completely fulfilled by one third of pupils. During the semester, some pupils collected the data needed for composing the mathematical problems containing developmental and interdisciplinary links, and teacher examined with them mathematical problems composed on the basis of the material compiled. The subsequent checkups were conducted at the end of the semester. Pupils' outcomes were increasingly higher during each subsequent checkup. During the fifth checkup, more than two-thirds of pupils completely fulfilled the task, which demonstrates the need for the inclusion of mathematical problems with developmental and interdisciplinary links in the teaching process, and this improves mathematics education.

In addition to the groups participating in the educational experiment, we also observed the groups selected for monitoring. The pupils' level of mathematical knowledge in these groups was almost the same. Average ratings were 7.5 and 7.4 respectively. Pupils from the experimental group collected the data needed for composing the mathematical problems containing developmental and interdisciplinary links, during the teaching process, they considered mathematical problems containing developmental and interdisciplinary links, and teaching was conducted in accordance with the described methodology, while in the groups selected for monitoring, teaching was conducted in the traditional format.

The effectiveness of the developed methodology was tested at the end of the semester in the form of problems assigned for final written test. Each test contained one question that contained in turn a mathematical problem with the content of developmental and interdisciplinary links, although this problem could also be solved in another way.

Let us take a statistical assessment of the solution of interdisciplinary and developmental mathematical problems for the experimental and control groups during the five semesters of the experiment. The table below shows the results of five checkups. The first checkup was aimed to determine the pupils' overall level of mathematical knowledge; the remaining four checkups were aimed to test mastering the approaches available.

Theexperimental and control groups have been assessed two criteria as follows:

1. How many pupils attempted to solve interdisciplinary and developmental mathematics problems?

2. Of them how many pupils were able to get a right solution.

The experimental results are given in Table 1.

Table 1

\begin{tabular}{|l|l|l|l|l|l|l|l|l|l|l|}
\hline Groups & \multicolumn{9}{|l|}{ Experimental } & \multicolumn{3}{l|}{ Control } \\
\hline Number of pupils & 310 & 310 & 310 & 310 & 310 & 295 & 295 & 295 & 295 & 295 \\
\hline $\begin{array}{l}\text { Solution } \\
\text { I }\end{array}$ & 199 & 201 & 202 & 208 & 200 & 162 & 164 & 167 & 173 & 169 \\
\hline Failed to solve & 111 & 109 & 108 & 102 & 110 & 133 & 131 & 128 & 122 & 126 \\
\hline $\begin{array}{l}\text { Solution } \\
\text { II }\end{array}$ & 155 & 156 & 157 & 159 & 153 & 110 & 112 & 113 & 115 & 120 \\
\hline Failed to solve & 44 & 45 & 45 & 49 & 47 & 52 & 52 & 54 & 58 & 49 \\
\hline
\end{tabular}

Since there is no large deviation from the solution of each problem, let's move on to the evaluation average values. We calculated the difference between these two values using the $\chi^{2}$ criterion [1]. The value $T_{\mathrm{kr}}$ of the criterion statistics for the data level and $\alpha=0,005$ and the degree $U$ of freedom $v=1$ from Table [1] is equal to 7.68 , that is, $T_{\mathrm{kr}}=7,68$. A null hypothesis $T_{0}$ is that the difference in test scores between the experimental and control group pupils is random. An alternative hypothesis $T_{1}$ - is statistical difference, that is, it is not random. The results are shown in Table 2. 
Table 2

\begin{tabular}{|l|l|l|}
\hline Groups & Experimental & Control \\
\hline Number of pupils & 310 & 295 \\
\hline $\begin{array}{l}\text { Solution } \\
\text { I }\end{array}$ & 202 & 167 \\
\hline Failed to solve & 108 & 128 \\
\hline $\begin{array}{l}\text { Solution } \\
\text { II }\end{array}$ & 158 & 114 \\
\hline Failed to solve & 44 & 53 \\
\hline
\end{tabular}

Forstatisticalcalculationofthecriterion $T_{n}$ oftheconductedexperiment, weusedthefollowingformula:

$$
T_{n}=2 \cdot \frac{N\left(O_{11} O_{22}-O_{12} O_{21}\right)^{2}}{n_{1} n_{2}\left(\mathrm{O}_{11}+O_{21}\right)\left(O_{12}+O_{22}\right)}
$$

The values in this formula are taken from tables 3 and 4, which in turn have been obtained from Table 2.

Table 3

\begin{tabular}{|l|l|l|}
\hline I sign & Experimental & Control \\
\hline Solved & $O_{11}=202$ & $O_{21}=167$ \\
\hline Failed to solve & $O_{12}=108$ & $O_{22}=128$ \\
\hline & $O_{11}+O_{12}=n_{1}=310$ & $O_{21}+O_{22}=n_{2}=295$ \\
\hline
\end{tabular}

Where $n_{1}+n_{2}=N=605$

Table 4

\begin{tabular}{|l|c|c|}
\hline I sign & Experimental & Control \\
\hline Solved & $O_{11}^{\prime}=158$ & $O^{\prime}{ }_{21}=114$ \\
\hline Failed to solve & $O_{12}^{\prime}=44$ & $O_{22}^{\prime}=53$ \\
\hline \multirow{2}{*}{} & $O_{11}^{\prime}+O^{\prime}{ }_{12}=n_{1}{ }^{\prime}=202$ & $O_{21}^{\prime}+O_{22}^{\prime}=n_{2}{ }^{\prime}=167$ \\
\cline { 2 - 3 }
\end{tabular}

Where $n_{1}^{\prime}+n_{2}^{\prime}=N^{\prime}=369$.

We got the following values:

For the first criterion $-T_{\mathrm{n}}=9,2913$ and for the second criterion $-T_{\mathrm{n}}^{\prime}=9,3499$. Since both values are greater than $T_{\mathrm{kr}}$, therefore, the decision-making hypothesis $T_{0}$ for both criteria is replaced by an alternative hypothesis $T_{1}$, that is, the differences by the first and second criterion between the experimental and control groups is not random. In the first and second signs are not random

Pupils in the experimental and control groups were under the almost identical training conditions, only difference was that one assignment contained the problem with the developmental and interdisciplinary links, so the obtained difference can be explained only by the fact that the inclusion of mathematical problems with the developmental and interdisciplinary links in primary school teaching practice in the experimental groups has proved to be effective.

- We also found that the mean scores of assessments in native language, nature study and fine and applied arts were significantly higher in the experimental groups participating in the educational experiment. In particular, the mean score in native language in the control groups was 8.7 at the beginning of the experiment, and 9.3 at the end of the experiment, in nature study, the relevant data were 8.1 and 8.7, and in fine and applied arts- 8.8 and 9.5, while in the control groups, the mean assessment scores were not changed significantly.

In addition, throughout the course of the educational experiment, we studiedchanges in the written and spoken forms of pupils in the experimental and control groups.

Studies have shown that the written and spoken forms of pupils in the experimental and control groups had become relatively more persuasive, they formulate and communicate their ideas clearly by highlighting the a key component of their idea. During the same period, there were no significant changes in the written and spoken forms of pupilsin the control group. 
Based on the above data, we can conclude that by including the methodology that we developed in the teaching process, the academic level of primary school pupils in mathematics and in their native language, natural sciences, and fine and applied arts increased significantly, as well as the level of general education of pupils improved markedly, The teaching process has become more attractive to primary school pupils, and solving mathematical problems in their teaching activities has become a pleasurable process( DavideN, Jeanne M, Jacky S, 2011).

\section{IV-Conclusions and recommendations}

The educational experiment allows us for making conclusions as follows:

1. The methodological approach that we developed - the inclusion of mathematical problems with developmental and interdisciplinary links in the in primary school practice has proved to be effective and its use in the teaching process is appropriate, it does not require additional time for teaching, has a developmental effect on pupils, serves to assimilate in depth the knowledge ofprimary school disciplines;

2. Mathematical problems with the content of developmental and interdisciplinary links should be included naturally in the teaching process in primary school, in accordance with the basic, particular topics of two or more school subjects, but one class should address one or two problems with the same content, one problem should be given as homework, which is similar to problem examined in classroom and is less complex.

3. The inclusion of mathematical problems with the content of developmental and interdisciplinary links in primary school teaching practice contributes to deepening pupils' mathematical knowledge, increases their intelligence, and motivates pupils to deeply and thoroughly study not only mathematics but also other subjects(Harding, Jessica $\mathrm{F}, 2015)$.

4. It is methodically justified to classify mathematical problems with the content of developmental and interdisciplinary links by level of complexity, and to consider the relatively more complex problems in classes, facultative and math circles activities, while giving simpler problemstopupilsas homework or for working independently. We find it unacceptable to include very complicated problems in the teaching process.

The developed methodological approaches allow for making teaching in primary school more effective, which will enhance pupils' self-confidence, will increase their interest in learning, will raise their intellectual level, and will provide the basis for in-depth and thorough school education. All this was confirmed by the educational experiment.

\section{References}

Andres, Hayward P. Active Teaching to Manage Course Difficulty and Learning Motivation.Journal of Further and Higher Education, v43 n2, 2019.

Batchelor, Sophie; Torbeyns, Joke; Verschaffel, Lieven.Affect and Mathematics in Young Children: An Introduction.Educational Studies in Mathematics, v100 n3 p201-209 Mar 2019.

Beilock, S.L., \& Maloney, E.A. (2015). Math anxiety: A factor in math achievement not to be ignored. Policy Insights from the Behavioral and Brain Sciences, 2(1), $4-12$.

Berk, L. E., \&Winsler, A. (1995). Scaffolding children's learning: Vygotsky and early childhood education. Washington, DC: National Association for the Education of Young Children.

Elbahri, M. Soliman, A. Yliniemi, K.Abdelaziz, R. Homaeigohar, S. Zarie, E.S. Innovative Education and Active Teaching with the LeidenfrostNanochemistry. Journal of Chemical Education, v95 n11, 2018.

Elmore, R.F.; Peterson, P.L.; McCarthy, S.J. 1996.Restructuring in the classroom: teaching, learning and school organization.San Francisco, CA, Jossey-Bass.

Frye, D., Baroody, A. J., Burchinal, M., Carver, S. M., Jordan, N. C., \& McDowell, J. (2013). Teaching math to young children: A practice guide (NCEE 2014-4005). Washington, DC: National Center for Education Evaluation and Regional Assistance (NCEE), Institute of Education Sciences, U.S. Department of Education

Ginsburg, H., Klein, A., \& Starkey, P. (1998). The development of children's mathematical thinking: Connecting research with practice. In I. Siegel \& K. Renninger (Eds.), Child psychology in practice (5th ed., pp. 401-476). New York, NY: Wiley.

Ginsburg, H. P., Lee, J. S., \& Boyd, J. S. (2008). Mathematics education for young children: What it is and how to promote it. Society for Research in Child Development, Social Policy Report, 22(1).

Godfrey, J., Stone, J. Mastering Fact Fluency: Are They Game?Teaching Children Mathematics, v20 n2, p96-101, 2013.

Harding, Jessica F. Increases in Maternal Education and Low-Income Children's Cognitive and Behavioral Outcomes.Developmental Psychology, v51 n5 p583-599 May 2015.

Marotta, S. M.; Hargis, J. Low-Threshold Active Teaching Methods for Mathematic Instruction.PRIMUS, v21 n4 p377-392 2011. 
Ronald V. Morris (2018) Innovation for Motivation: First-person presentations, Childhood Education, 94:5, 1422, DOI:10.1080/00094056.2018.1516468

Stella Vosniadou. (2001).How children learn. International Academy of Education (IAE) Educational Practices series7. " Learning requires the active, constructive involvement of the learner

Understanding the Role of Objects in Cross-Disciplinary Collaboration, DavideNicolini, Jeanne Mengis, Jacky Swan, 2011.

Vukovic, Rose K.; Lesaux, Nonie K.The Language of Mathematics: Investigating the Ways Language Counts for Children's Mathematical Development. Journal of Experimental Child Psychology, v115 n2 p227-244 Jun 2013.

Wickstrom, Hanna; Pyle, Angela; DeLuca, Christopher. Does Theory Translate into Practice? An Observational Study of Current Mathematics Pedagogies in Play-Based Kindergarten.Early Childhood Education Journal, v47 n3. May 2019. 